\title{
Frequency of Dental Caries \& Oral Hygiene Practices Among Female College Students
}

\section{Fareeha Sajjad}

BDS, MPH

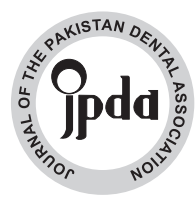

BACKGROUND: Dental caries is believed a leading public health dilemma worldwide owing to its high incidence and considerable social impact. Mostly females have higher score of DMF (decayed, missing and filled) than the same age of males. Females are considered pillars of the society because they have to train future children. Hence there is great need to provide knowledge to the females regarding dental caries and oral hygiene, who are entering in family generation phase, as by boosting oral hygiene most prevalent disease i.e. dental caries could be prevented.

OBJECTIVES: The objectives of the study were to find out frequency distribution of dental caries among female college students and to assess the practices regarding oral hygiene and dental caries.

METHODOLOGY: It was cross-sectional descriptive study in which 80 female college students were included. Data was collected through questionnaire, which was entered into computer using SPSS 17.0.

RESULTS: Among 80 female college students, $80.0 \%$ were $19-22$ years old, 50.0\% cleaned their teeth once a day and $100.0 \%$ used toothbrush. $65.0 \%$ students' toothpaste contained fluoride. Among students $52.5 \%$ had no decayed and $82.5 \%$ had 0 missed tooth and $50.0 \%$ had 0 filled tooth. The mean DMFT score was 2.30 .

CONCLUSION: Large number of students brushed their teeth once or twice daily. Overall oral health of female students was found satisfactory.

KEY WORDS: Caries, oral hygiene, DMF, females, Lahore.

HOW TO CITE: Sajjad F. Frequency of Dental Caries \& Oral Hygiene Practices Among Female College Students. J Pak Dent Assoc 2017;26(4):171-75.

DOI: https://doi.org/10.25301/JPDA.264.171

Received: 18 September, 2017, Accepted: 31 October, 2017

\section{INTRODUCTION}

$\mathrm{H}$ ealth is a condition of physical, mental, social well-being and not merely the absence of illness or infirmity. ${ }^{1}$ Dental disease is one of the most prevalent diseases globally. ${ }^{2}$ The oral health is described as "it is a structural, functional, aesthetic, psychosocial and physiologic state of well-being and necessary for quality of life and general health of an individual. ${ }^{3}$ Oral hygiene plays a considerable role in oral health maintenance. Inadequate oral hygiene is a major risk factor for the development of oral diseases. ${ }^{4}$

Oral hygiene is a practice of keeping teeth and mouth clean to avoid dental issues, particularly bad breadth, gingivitis and dental caries. The main reason of keeping oral hygiene is to protect the plaque buildup, sticky layer of the bacteria and food that appears on teeth. ${ }^{5}$ More than 80 percent persons are affected by dental plaque, making it most communicable disease present among people. ${ }^{6}$

Oral diseases are believed most significant public health issue owning to their high incidence and main social impact system. ${ }^{7}$ Dental caries is most prevalent oral disease. It is

Institute of Public Health, Lahore

Corresponding author: "Dr. Fareeha Sajjad" < f-m-100@ hotmail.com > a chronic sugar dependent communicable disease, affecting the calcified tissue of tooth and causing demineralization of inorganic part with later damage of organic material. Carious tooth can never return to its original condition, although it is treated. ${ }^{8}$

Maintenance of oral hygiene has an imperative role in the formation of caries. Due to poor oral hygiene the risk of caries can be increased. Carbohydrates boost the chance of tooth decay. The most harmful are sticky foods as they stay on teeth. Recurrent snacking enhances the time that acids are in exposure with tooth surface therefore it is a risk factor as well. ${ }^{9}$ Other causes includes lack of sufficient fluorides. Fluoride helps in preventing tooth decay through making teeth extra resistant to the acids generated by plaque. ${ }^{10}$

Dental caries is believed a leading public health dilemma worldwide owing to its high incidence and considerable social impact. ${ }^{11}$ WHO (World Health Organization) highlights that $60 \%$ to $90 \%$ of adults and school children have experienced dental caries worldwide, with the disease being most widespread in Latin American and Asian countries. ${ }^{12}$ Globally, the prevalence of dental caries in

20-64 years age groups is $92 \%$ while in 20-30 year group is $85.58 .{ }^{13} \mathrm{~A}$ study conducted in Iraq demonstrated that 
prevalence of caries is more among females $(84.61 \%)$ than males $(71.63 \%) .{ }^{8}$ As per Pathfinder Research carried out in collaboration with World Health Organization in Pakistan, $52 \%$ cases in $12-15$ years age group and 70\% in 35-64 years age group had dental caries. The incidences of dental caries enhanced with age. ${ }^{14}$ One more study performed in Karachi demonstrated $51 \%$ prevalence of caries in 3-6 years age group $^{15}$. A study undertaken in Lahore showed $60.90 \%$ prevalence of dental caries in 3-8 years age group. ${ }^{16}$

Mostly females have higher score of DMF (decayed, missing and filled) than the same age of males. Although, currently it is supposed that an atmosphere with its standard life style, dietary pattern, culture and socio-economic status can keep a significant impact on the development or resistance of caries than so-called intrinsic ethnic attributes. ${ }^{17}$

Pupils are separate portion of the population differentiated by a particular age and certain way of the life..$^{18}$ The entire level of health in young people student life is affected by numerous factors, for example, raised psycho-emotional stress and inadequate social and hygienic conditions. The reliance of increase of the dental disease prevalence from rhythm of the life, level of hygienic culture, education, medical care and dietary habits has been recognized in several investigations. ${ }^{19}$ The most useful technique to maintain health during study period is medical examination which allows to reveal symptoms of the teeth and gums lesions during early phases and provides total recovery about diagnosed deformities..$^{20} \mathrm{~A}$ recent study regarding oral health of students and development of medical programs have explained by several authors. ${ }^{21}$ This part of population deserves special attention because it is enough large and has a great potential health dentition. ${ }^{18}$

Females are considered pillars of the society because they have to train future children. Hence there is great need to provide knowledge to the females regarding dental caries and oral hygiene, who are entering in family generation phase, as by boosting oral hygiene most prevalent disease i.e. dental caries could be prevented. Therefore present study aims to know the frequency of dental caries and associated oral hygiene practices in female college students.

The strength of this study was that it can be generalized to the female population who are studying in colleges of Lahore, as the samples were selected randomly to ensure that the results will be representative of the population studied. Moreover standardized approach was used which permits the study to be replicated in different areas or over time with the production of comparable findings.

In contrast the limitation of this study includes that it was limited to female students studying in college, No similar study was present in Lahore of this age group for comparison of results.

\section{METHODOLOGY}

It was cross-sectional descriptive study in which 80 female students of Government College of Home Economics, Gulberg Lahore were included. The inclusion criteria was female students enrolled in BS program while the exclusion criteria was students who were absent, unwilling to participate and already receiving any dental treatment. The duration of study was three months (from Feb. to April 2016). Simple random sampling technique was used. There were total 4 level of classes $\left(1^{\text {st }}\right.$ year to $4^{\text {th }}$ year) in the college. In each class there were 200 students, making total of 800 students. From each class researcher selected $10 \%$ of students. Data was collected through questionnaire (circulated in each class by its class representative), which was first pretested in small setup and then was submitted to the students who afterwards were checked by the examiner for DMFT scoring, it was then entered into computer using SPSS 17.0. Frequencies and percentages were calculated and data was presented in tabulation form. Confidentiality of the data was ensured and proper consent was obtained before data collection.

\section{RESULTS}

Response rate was $100 \%$, as random students who were willing to participate were selected.

Among 80 female college students, $8(10.0 \%)$ were $\leq 18$ years old and majority $64(80.0 \%)$ was $19-22$ years old while $8(10.0 \%)$ students were more than 22 years old (Table-1).

Among 80 students, 30 (37.5\%) cleaned their teeth twice a day while majority $40(50.0 \%)$ once a day and only 10 $(12.5 \%)$ students cleaned their teeth occasionally. As far as different methods for teeth cleaning are concerned, table describes that all (100.0\%) students used toothbrush. Among them 28 (35.0\%) also used toothpicks, 14 (17.5\%) thread (dental floss),4 (5.0\%) Miswak,34(42.5\%) mouthwash and $14(17.5 \%)$ students used sugar free gums to clean their teeth. Among 80 students, $52(65.0 \%)$ explained that they use a toothpaste that contains fluoride and only $2(2.5 \%)$ said no while 26(32.5\%) students were not aware about fluoride (Table-2.)

Among 80 students, 40 (52.5\%) had no decayed, $24(30.0 \%)$ had 1 decayed and $8(10.0 \%)$ had 2 decayed while $6(7.5 \%)$ students had $>2$ decayed. The mean decayed was 0.92 . Likewise among 80 students, majority $66(82.5 \%)$ had 0 missed tooth, 10(12.5\%) had 1 missed tooth and 2 $(2.5 \%)$ had 2 missed teeth while $2(2.5 \%)$ students had $>2$ missed teeth. The mean missed was 0.28 . Among 80 students, $40(50.0 \%)$ had 0 filled tooth, $24(30.0 \%)$ had 1 filled tooth and $6(7.5 \%)$ had 2 filled teeth while $10(12.5 \%)$ students had $>2$ filled teeth. The mean filled was 1.10 (Table-3). 
Among 80 students, 20 (25.0\%) had 0 DMFT score, $14(17.5 \%)$ had 1 DMFT score, 22(27.5\%) students had 2 DMFT score and $10(12.5 \%)$ had 3 DMFT score while 14 $(17.5 \%)$ students had $>3$ DMFT score. The mean DMFT score was 2.30 (Table-4).

Table-1: Distribution of female students by age

\begin{tabular}{|l|c|c|}
\hline & Frequency & Percentage (\%) \\
\hline$\leq 18$ years & 8 & 10 \\
\hline $19-22$ years & 64 & 80 \\
\hline$>22$ years & 8 & 10 \\
\hline Total & 80 & 100.0 \\
\hline
\end{tabular}

Fig.-1: Distribution of female students by age

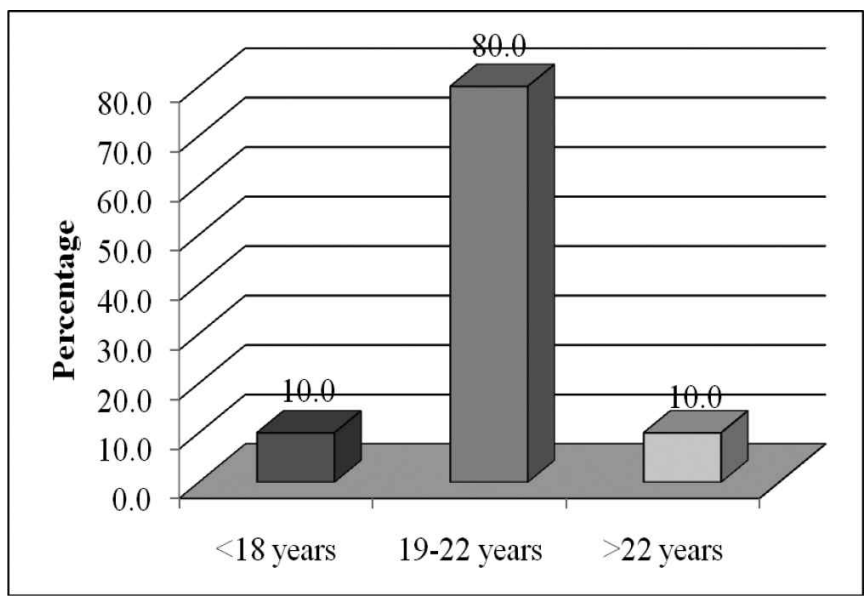

Table-2: Distribution of female students by oral hygiene practices

\begin{tabular}{|l|c|c|}
\hline & Frequency & Percentage (\%) \\
\hline Frequency of teeth cleaning \\
\hline Twice a day & 30 & 37.5 \\
\hline Once a day & 40 & 50.0 \\
\hline Occasionally & 10 & 12.5 \\
\hline Total & 80 & 100.0 \\
\hline Method used for teeth cleaning \\
\hline \multicolumn{2}{|l|}{ Toothbrush } \\
\hline Yes & 80 & 100.0 \\
\hline No & 0 & 0.0 \\
\hline Total & 80 & 100.0 \\
\hline Toothpicks & 28 & 35.0 \\
\hline Yes & 52 & 65.0 \\
\hline No & 80 & 100.0 \\
\hline Total & 14 & 17.5 \\
\hline Thread (dental floss) & 66 & 82.5 \\
\hline Yes & 80 & 100.0 \\
\hline No & \multicolumn{2}{|l|}{} \\
\hline Total
\end{tabular}

\begin{tabular}{|l|c|c|}
\hline Miswak & 4 & 5.0 \\
\hline Yes & 76 & 95.0 \\
\hline No & 80 & 100.0 \\
\hline Total & 34 & 42.5 \\
\hline Mouthwash & 46 & 57.5 \\
\hline Yes & 80 & 100.0 \\
\hline No & 14 & 17.5 \\
\hline Total \\
\hline Sugar free gums \\
\hline Yes & 66 & 82.5 \\
\hline No & 80 & 100.0 \\
\hline Total & 52 & 65.0 \\
\hline Use toothpaste that contains fluoride \\
\hline Yes & 2 & 2.5 \\
\hline No & 26 & 32.5 \\
\hline Don't know & 80 & 100.0 \\
\hline Total &
\end{tabular}

Table-3: Distribution of female students by dental caries

\begin{tabular}{|l|c|c|}
\hline & Frequency & Percentage (\%) \\
\hline Decayed & 42 & 52.5 \\
\hline 0 & 24 & 30.0 \\
\hline 1 & 8 & 10.0 \\
\hline 2 & 6 & 7.5 \\
\hline$>2$ & 80 & 100.0 \\
\hline Total & \\
\hline \multicolumn{2}{|c|}{ Mean \pm SD $=0.92 \pm 1.73$} \\
\hline Missing \\
\hline 0 & 66 & 82.5 \\
\hline 1 & 10 & 12.5 \\
\hline 2 & 2 & 2.5 \\
\hline$>2$ & 2 & 2.5 \\
\hline Total & 80 & 100.0 \\
\hline \multicolumn{3}{|c|}{ Mean \pm SD $=0.28 \pm 0.74$} \\
\hline Filled & 40 & 50.0 \\
\hline 0 & 24 & 30.0 \\
\hline 1 & 6 & 7.5 \\
\hline 2 & 10 & 12.5 \\
\hline$>2$ & 80 & 100.0 \\
\hline Total & \\
\hline \multicolumn{2}{|c|}{} \\
\hline
\end{tabular}

Table-4: Distribution of female students by DMFT score

\begin{tabular}{|l|c|c|}
\hline & Frequency & Percentage (\%) \\
\hline 0 & 20 & 25.0 \\
\hline 1 & 14 & 17.5 \\
\hline 2 & 22 & 27.5 \\
\hline 3 & 10 & 12.5 \\
\hline$>3$ & 14 & 17.5 \\
\hline Total & 80 & 100.0 \\
\hline \multicolumn{2}{|c|}{ Mean $\pm \mathrm{SD}=2.30 \pm 2.53$} \\
\hline
\end{tabular}




\section{DISCUSSION}

Present study was conducted to assess the frequency of dental caries and oral hygiene practices among female college students of Government College of Home Economics, Gulberg Lahore. To acquire appropriate outcomes, a group of 80 students (first year to fourth years) was included in the study and found that mainstream of students was 19-22 years old while few of them were less than 18 or more than 22 years old.

Regular teeth cleaning is good habit that prevents people not only from dental caries but also from numerous oral diseases. Study revealed that major proportion $(50.0 \%)$ of students cleaned their teeth once daily, followed by twice daily $(37.5 \%)$ and occasionally (12.5\%). The results of the study conducted by Kakkad and coworkers (2014) exhibited better scenario than our study results who reported that $30.8 \%$ students cleaned their teeth once daily, majority $(67.0 \%)$ twice daily while $1.0 \%$ and $1.2 \%$ more than twice and after every meal, respectively. ${ }^{22}$ Another study carried out by Manna and coworkers (2014) showed that 36.4\% female students cleaned their teeth at night. ${ }^{23}$

These days toothbrush is considered one of the best instruments for teeth cleaning while significant role of toothpaste can also not be ignored in preventing dental caries and mainstream of population use tooth paste with brush for teeth cleaning. It is important to mention that $100.0 \%$ student used toothbrush for teeth cleaning. Study further revealed that $35.0 \%, 17.5 \%, 5.0 \%, 42.5 \%$ and $17.5 \%$ used toothpicks, thread (dental floss), Miswak, mouthwash and sugar free gums to clean their teeth, respectively. Manna and coworkers (2014) asserted in their study that virtually $67.4 \%$ students used toothbrush and toothpaste regularly for tooth cleaning while the other materials were floss $(2.3 \%)$, toothpick (2.3\%), charcoal $(0.8 \%)$ and chew stick $(0.8 \%){ }^{23}$

Fluoride is extremely beneficial in preventing caries and making teeth stronger. Study revealed that more than half of female students used tooth paste that contained fluoride.

Study highlighted that more than half of the female students had no decayed while $47.5 \%$ had decayed teeth. The results of our study exhibited better scenario than the study conducted by Kaur and teammates (2010) who asserted that $70.0 \%$ female students had decayed teeth. ${ }^{24}$ While the study undertaken by Manna and coworkers (2014) showed better results that only $19 \%$ female students had complain of having decayed teeth. ${ }^{23}$

When missed or filled teeth were assessed among female college students, study divulged that only $17.5 \%$ had missing and $50.0 \%$ had filled teeth. Though the prevalence of filled teeth is higher in our study population but still results of our study are better than the study carried out by El-Khateeb and colleagues (2015) who reported that $56.5 \%$ females had missing and $61.8 \%$ had filled teeth. ${ }^{25}$

During study DMFT score of female college students was also assessed and found that $25.0 \%$ students had 0 score, $17.5 \%$ had 1 score, $27.5 \%$ had 2 scores and $12.5 \%$ had 3 scores while $17.5 \%$ had $>3$ scores. The results of the study conducted by Manna and coworkers (2014) are better than our study result who confirmed that majority $(62.8 \%)$ had 0 DMFT score while $14.4 \%, 14.4 \%, 2.3 \%$ and $6.1 \%$ had 1 , 2, 3 and $>3$ scores, respectively. ${ }^{23}$ The overall mean DMFT was 2.30 among female college students while the study done by Al Essa and assoicates (2007) showed that overall mean DMFT was 10.01. ${ }^{26}$ Another study undertaken by Fayaz and Sivakumaar (2014) showed almost similar results who reported that DMFT score of female students was $2.32 .{ }^{1}$

Study was limited to female students of Government College of Home Economics, Gulberg Lahore.

\section{CONCLUSION}

Study found most of the students were 19-22 years old. All of them used toothbrush while significant majority used toothpaste with brush for teeth cleaning. Major proportion brushed their teeth once or twice daily. Use of fluoride was observed among most of the students. Overall oral health of female students was found satisfactory. The mean DMFT score was 2.30. Health education programs at college level are essential to prevent female students from dental caries.

\section{CONFLICT OF INTEREST}

None declared

\section{REFERENCES}

1. Fayaz M, Sivakumaar PK. Prevalence of dental caries among the research scholars of Annamalai University in relation of different factors associated. Golden Res Thoughts. 2014;3:1-7.

2. Petersen PE. The world oral health report 2003. Continuous improvement of oral health $n$ the 21 st century - the approach of the WHO Global Oral Health Programme. Geneva: World Health Organization; 2003.

3. American Dental Association (ADA). ADA policy: definition of oral health [online] 2015 [accessed 7 July 2015]. Available at: http://www.ada.org/en/about-the-ada/adapositions-policies-and-statements/ada-policy-definition-oforal-health.

4. World Health Organization (WHO). Oral health [online] 2015 [accessed 7 July 2015]. Available at: 
http://www.who.int/topics/oral_health/en/.

5. Iqbal F, Fahad S. Knowledge, attitude \& practices regarding oral health among 6th grade students of two local schools in Mardan. J Pak Dent Assoc. 2014;2:122-5. 6. Kabir S, Gul R. Knowledge, attitude and practices regarding oral hygiene in school going children of both genders, aged 10-15 years. J Khyber Coll Dent. 2013;3:8-13. 7. Khan F, Ayub A, Kibria Z. Knowledge, Attititude and practice about oral health among general population of Peshawar. J Dow Uni Health Sci. 2013;7:117-21. 8. Huda A. Abdullah. Prevalence of dental caries and associated teeth brushing behaviour among Iraqi adolescents in Al-Door district. Tilkrit Med J. 2009; 15: 102-9. 9. Medline Plus. Dental cavities [online] 2015 [accessed 7 July 2015]. Available at: http://www.nlm.nih.gov/med lineplus/ency/article/0010 55.htm.

10. WebMD. Tooth decay-topic overview [online] 2015 [accessed 7 July 2015]. Available at: http://www.web $\mathrm{md} . c 0 \mathrm{~m} /$ oral-health/tc/tooth-decay-topic-overview. 11. Dixit LP, Shakya A, Shrestha M, Shrestha A. Dental caries prevalence, oral health knowledge and practice among indigenous Chepang school children of Nepal. BMC Oral Health. 2013; 13: 20.

12. Dixit PL, Shakya A, Shrestha M, Shrestha A. Dental caries prevalence, oral health knowledge and practice among indigenous Chepang school children of Nepal. BMC Oral Health. 2013; 13: 20.

13. National Institute of Dental and Craniofacial Research. Dental caries (tooth decay) in adults (age 20 to 64) [online] 2015 [accessed 7 July 2015]. Available at: http://www.nidcr.nih.gov/DataStatistics/FindData ByTopic/DentalCaries/DentalCariesAdults20to64.htm. 14. Maher R. Dental disorders in Pakistan: a national pathfinder survey. J Pak Med Assoc. 1991; 41: 250-2. 15. Dawani N, Nisar N, Khan N, Syed S, Tanweer N. Prevalence and factors related to dental caries among preschool children of Saddar town, Karachi, Pakistan: a crosssectional study. BMC Oral Health. 2012; 12: 59. 16. Mirza BAQ, Chohan AN, Sajid M, Kahlown RA. Dental caries prevalence in 3-8 years old children of Army Schools in Lahore. Pak Oral Dent J. 2013; 33: 364-6.

17. Rehman MMU, Mahmood N, Rehman BU. The relationship of caries with oral hygiene status and extra-oral risk factors. J Ayub Med Coll Abbottabad. 2008; 20:103-8. 18. Yurievna LE, Borisovna NI, Borisovna NY. Dental disease incidence among the students of Rostov State Medical University (Section 6). Vienna: European Science Review;2015, pp. 35-37.

19. Protsenko AS, Makeeva IM. Factors influencing the prevalence of major dental diseases among students of Moscow. Dent. 2010; 1: 4-6.

20. Doroshina VY, Makeeva IM, Protsenko AS. Dental health examinations of students of Moscow Universities and ways to improve its efficiency. Dent. 2010; 1: 7-9. 21. Davydov BN, Gavrilova OA, Shevayakova MA. Prevalence and intensity of dental diseases among foreign students during their training in Russia. Dent. 2011;1:22-4. 22. Kakkad DN, Murali R, Krishna M, Yadav S, Yalamalli M, Kumar AV. Assessment of oral hygiene knowledge, attitude, and practices among engineering students in North Bangalore: a cross-sectional survey. Int J Scientific Stud. 2015; 3: 84-9.

23. Manna N, Biswas S, Pandit D, Mondal K, Baur B, Mundle M. Oral hygiene practice and health status among adolescent girls - a rural school based study. J Dent Med Sci. 2014; 13: 29-33.

24. Kaur R, Kataria H, Kumar S, Kaur G. Caries experience among females aged 16-21 in Punjab, India and its relationship with lifestyle and salivary HSP70 levels. Eur J Dent. 2010;4: 308-13.

25. El-Khateeb SM, Jaber S, Alghamdi B, Jaafar A, DarOdeh N. Prevalence of dental caries among young women in central western region of Saudi Arabia. Int J Adv Dent Med Sci. 2015; 1: 46-9.

26. Al Essa NA, Al Mutairi MA, Al Ohali HM, El Hejazi A, Chohan A. Caries, oral hygiene status and dates consumption among Saudi Female university students. Afaq Dent Mag. 2007; 15: 40-6. 